\title{
Correlation between Manchester Grading Scale and American Orthopaedic Foot and Ankle Society Score in Patients with Hallux Valgus
}

\author{
Kalliopi lliou $^{a}$ George Paraskevas $^{b}$ Panagiotis Kanavaros ${ }^{a}$ \\ Alexandra Barbouti $^{a}$ Aristidis Vrettakos ${ }^{a}$ Christos Gekas $^{b}$ \\ Panagiotis Kitsoulis ${ }^{\mathrm{a}}$ \\ a Department of Anatomy-Histology-Embryology, School of Medicine, University of loannina, loannina, and \\ ${ }^{b}$ Department of Anatomy-Histology-Embryology, School of Medicine, Aristotle University of Thessaloniki, \\ Thessaloniki, Greece
}

\section{Key Words}

Hallux valgus · Manchester Grading Scale .

American Orthopaedic Foot and Ankle Society score

\begin{abstract}
Objective: To evaluate the correlation between the Manchester Grading Scale and the American Orthopaedic Foot and Ankle Society (AOFAS) score in patients with a hallux valgus deformity. Subjects and Methods: The study sample included 181 feet of 122 patients with hallux valgus and 424 feet of 212 individuals without hallux valgus deformity as the control group. The severity of hallux valgus, utilizing a relative nonmetric scale, the Manchester Grading Scale, and the metric AOFAS score, was determined for all individuals in the hallux valgus and control groups. SPSS version 18 (Chicago, III., USA) was used for data analysis. Results: According to the Manchester Grading Scale, the 424 feet of the normal group were classified as 'no deformity'. In the hallux valgus group, 85 feet were classified as 'mild deformity', 67 as 'moderate deformity' and 29 as 'severe deformity'. The AOFAS total score in the control group was 99.14. In the hallux valgus group, patients with mild or moderate deformity had total scores of 86.20 and 68.19 , respectively. For those with severe hallux valgus, the total score was 44.69 and the differences
\end{abstract}

\begin{tabular}{|c|c|}
\hline KARGER & $\begin{array}{l}\text { (c) } 2015 \text { S. Karger AG, Basel } \\
1011-7571 / 15 / 0251-0021 \$ 39.50 / 0\end{array}$ \\
\hline $\begin{array}{l}\text { E-Mail karger@karger.com } \\
\text { www.karger.com/mpp }\end{array}$ & $\begin{array}{l}\text { This is an Open Access article licensed under the terms of the } \\
\text { Creative Commons Attribution-NonCommercial 3.0 Un- } \\
\text { ported license (CC BY-NC) (www.karger.com/OA-license), } \\
\text { applicable to the online version of the article only. Distribu- } \\
\text { tion permitted for non-commercial purposes only. }\end{array}$ \\
\hline
\end{tabular}

were statistically significant $(p=0.000)$. Using the Pearson correlation, strong negative correlations were found between the AOFAS score and the hallux valgus angle (HVA; $r=-0.899, p=0.000$ ). Strong negative correlations were demonstrated between the AOFAS score and the first intermetatarsal angle (IMA) as well $(r=-0.748, p=0.000)$. Conclusions: The AOFAS score was negatively associated with the Manchester Grading Scale, HVA and first IMA. As the severity of hallux valgus increased, the AOFAS score seemed to decrease.

(c) 2015 S. Karger AG, Basel

\section{Introduction}

Hallux valgus is one of the commonest foot problems presenting with pain and gait dysfunction. In adults, the condition is present in $23 \%$ of the population aged between 18 and 65 years [1]. The impact of several foot conditions, such as hallux valgus, on daily activities, footwear requirements, joint motion, pain and foot alignment, is well documented in the American Orthopaedic Foot and Ankle Society (AOFAS) score [2]. Previous studies report a significant association between hallux valgus and foot pain $[3,4]$. The impact of moderate and severe hallux val- 


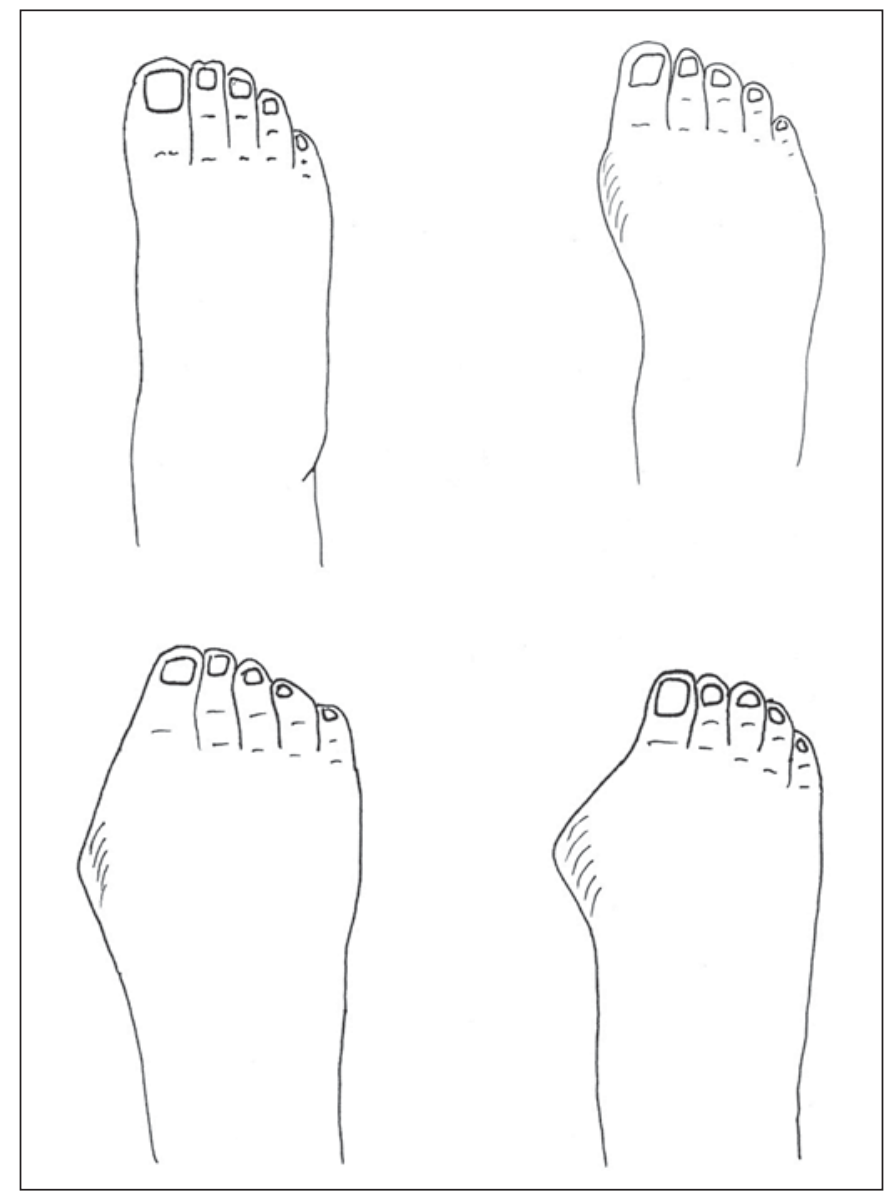

Fig. 1. Drawings of the foot based on the original photographs taken by Garrow et al. [12].

gus on gait and footwear-associated difficulties has also been well established in several studies $[3,5,6]$.

Radiographic assessment of hallux valgus includes the evaluation of the hallux valgus angle (HVA) as well as the first-second intermetatarsal angle (IMA) [7]. An HVA $<15^{\circ}$ and a first IMA $<9^{\circ}$ are considered normal [8]. Based on radiological assessment, hallux valgus is defined as mild, moderate and severe [9]. As it is not always feasible or necessary to perform an X-ray evaluation of the deformity, other simpler methods for classification have been suggested [10,11] including drawing around the foot [9] and the contour measurement of the foot using tapes [11]. The Manchester Grading Scale was proposed in 2001 by Garrow et al. [12] as an easier and simplified method for evaluating the severity of hallux valgus. It is a clinical method that uses a standardized set of foot photographs and describes 4 levels of hallux valgus: 'no deformity', 'mild deformity', 'moderate deformity' and 'severe defor- mity'. Hence, the aim of this study was to evaluate the correlation between the Manchester Grading Scale and the AOFAS preoperative score in patients with a hallux valgus deformity.

\section{Subjects and Methods}

The study sample included 181 feet of 122 patients (104 women and 18 men) with hallux valgus and 424 feet of 212 individuals (114 women and $98 \mathrm{men}$ ) without hallux valgus deformity as a control group. The weight in kilograms and height in meters of the participants were measured and the BMI calculated. An independent physician (C.G.) evaluated the severity of hallux valgus using the Manchester Scale; the original photographs from the publication by Garrow et al. [12] were used (fig. 1). Patients stood in a fullweight-bearing position and the degree of hallux valgus was recorded as no deformity, mild deformity, moderate deformity and severe deformity.

HVA and first IMA were measured using a goniometer which was placed directly on the feet, and the deformity was described as mild, i.e. an HVA $<20^{\circ}$ and a first IMA $\leq 11^{\circ}$, moderate, i.e. an HVA $20-40^{\circ}$ and a first IMA $<16^{\circ}$ and severe, i.e. an HVA $>40^{\circ}$ and a first IMA $\geq 16^{\circ}$. The AOFAS score was determined for all individuals in the hallux valgus and control groups by a trained professional (C.G.).

The data were analyzed using SPSS version 18.0 (Chicago, Ill., USA). The Kolmogorov-Smirnov test and Shapiro-Wilk test of normality were used to determine whether or not the data were normally distributed. For data analysis, the Pearson correlation, the nonparametric Kruskal-Wallis test and the Mann-Whitney U test were used. The means and standard deviations of the variables were recorded for their descriptive statistical analysis. A p value $<0.05$ was considered to represent a statistically significant difference. The confidence interval was $95 \%$.

\section{Results}

In the hallux valgus group, the mean age was $61 \pm 8.3$ years (range 18-78) while that of the control group was $52 \pm 10.1$ years (18-75). The BMI of the hallux valgus and control groups was $24.38 \pm 2.91$ and $23.97 \pm 2.31$, respectively. The mean total AOFAS score of the control group was $99.14 \pm 3.3$, while that of the patients with hallux valgus was $66.36 \pm 16.7$; the difference was statistically significant $(\mathrm{p}=0.000)$. According to the Manchester Grading Scale, the 424 feet of the control group were classified as normal (no deformity). Of the 181 feet of the hallux valgus group, 85 (46.7\%) were classified as mild, 67 (37.0\%) as moderate and $29(16 \%)$ as severe deformity (table 1). Based on the extent of the deformity, in the hallux valgus group, the AOFAS scores were $86.20 \pm 6.9$ (mild), $68.19 \pm 15.72$ (moderate) and $44.69 \pm 10.0$ (se- 
Table 1. Manchester Scale grades of feet with hallux valgus

\begin{tabular}{lll}
\hline $\begin{array}{l}\text { Manchester Grading } \\
\text { Scale }\end{array}$ & $\begin{array}{l}\text { Number } \\
\text { of feet }\end{array}$ & Incidence \\
\hline Mild deformity & 85 & $46.7 \%$ \\
Moderate deformity & 67 & $37.0 \%$ \\
Severe deformity & 29 & $16 \%$ \\
\hline
\end{tabular}

vere), and the differences were statistically significant $(\mathrm{p}=0.000)$. Using the Pearson correlation, strong negative correlations were found between the AOFAS score and the HVA $(\mathrm{r}=-0.899, \mathrm{p}=0.000)$. Strong negative correlations were demonstrated between the AOFAS score and the first IMA as well $(\mathrm{r}=-0.748, \mathrm{p}=0.000)$.

\section{Discussion}

In this study, there was a high negative correlation between the Manchester Grading Scale and AOFAS score. As the severity of hallux valgus increased, the AOFAS score decreased, i.e. the pain became more severe and foot function seemed to be restricted. Since 2001, when Garrow et al. [12] first presented the Manchester Scale, several reports about this clinical grading method have been published. Most of them investigated the correlation between both HVA and IMA with the Manchester Grading Scale. D'Arcangelo et al. [13] reported a strong correlation between both these angles and the Manchester Grading Scale. Menz and Munteanu [14] also reported the same strong correlation in 95 patients, but only for the HVA, and a weaker association for the first IMA. As an association between the Manchester Grading Scale, HVA and first IMA has thus already been established, we did not evaluate these parameters. Including a larger number of subjects than previous studies, we investigated the correlation between the Manchester Grading Scale and AOFAS score, which, to the best of our knowledge, has not yet been undertaken. Our findings agree with previous reports that greater angles induce pain and restrict foot mobility. Our study supports that a strong negative correlation between Manchester Grading Scale and AOFAS score exists.

Our findings indicate that the Manchester Grading Scale could be a useful clinical tool, providing information not only about the severity of the hallux valgus, but also about the general condition of the foot, pain and gait parameters, supporting a previous study [15] that sug-

Manchester Grading Scale gested that Manchester grading could be used to document the presence and severity of hallux vagus.

This grading method could also be used in large epidemiological studies [16] as a screening instrument because it is easy and noninvasive [16]. Recently, in another study [17], we observed that the Manchester Grading Scale is strongly correlated with both the HVA and firstsecond IMA. We also demonstrated that the correlation between the severity of hallux valgus, documented using the Manchester Grading Scale, and the peak pressure distribution beneath the hallux, first and second metatarsal heads could indicate the progression from mild to moderate and severe deformity, associated with increases in peak pressure at these areas [17]. This increase in peak pressure is probably one of the factors associated with the AOFAS score distribution in this study.

Pain evaluation is of one the most important factors for patients and orthopaedic surgeons when dealing with hallux valgus deformity [18]. At the same time, the cosmetic appearance of the foot is also a factor that a lot of patients consider as most important [2]. The presence of hallux valgus affects the patient's balance, gait patterns, risk of falling and quality of life. Most previous reports [19-21] about the impact of hallux valgus on the general condition of the foot only paid attention to the presence or absence of the deformation. However, Menz et al. [22], in a very detailed study, reported that as the severity of the deformity increased, all scores related to quality of life decreased, despite adjusting for age, sex, BMI, education and pain in the back, hips and knees. We have found results comparable to theirs; the AOFAS score which was used in our study paid attention not only to foot pain, but also to foot appearance, activity level and shoe requirements.

\section{Conclusion}

In this study, the Manchester Grading Scale was correlated with the AOFAS score. Strong negative correlations were also observed between AOFAS score and HVA and first IMA. As the severity of hallux valgus increased, the AOFAS score seemed to decrease. Hence, a moderate or severe deformity was more painful and limiting for patients when they were first seen in everyday orthopaedic practice.

\section{Acknowledgements}

We are grateful to an undergraduate medical student, Zoi Nitsa, for the drawings. 


\section{References}

$>1$ Nix S, Smith M, Vicenzino B: Prevalence of hallux valgus in the general population: a systematic review and meta-analysis. J Foot Ankle Res 2010;3:1-9.

$>2$ Rodrigues R, Masiero D, Mizusaki J, et al: Translation, cultural adaptation and validation of the 'American Orthopaedic Foot and Ankle Society's (AOFAS) Ankle-Hindfoot Scale'. Acta Ortop Bras 2008; 16:107-111.

$\checkmark 3$ Nix S, Vicenzino B, Smith M: Foot pain and functional limitation in healthy adults with hallux valgus: a cross-sectional study. BMC Musculoskelet Disord 2012;13:1-10.

$\checkmark 4$ Menz HB, Morris ME: Determinants of disabling foot pain in retirement village residents. J Am Podiatr Med Assoc 2005;95:573579.

$\checkmark 5$ Menz HB, Roddy E, Thomas E, et al: Impact of hallux valgus severity on general and footspecific health-related quality of life. Arthritis Care Res 2011;63:396-404.

6 Menz HB, Lord SR: Gait instability in older people with hallux valgus. Foot Ankle Int 2005;26:483-489.

7 Hardy RH, Clapham JCR: Observations on hallux valgus based on a controlled series. J Bone Joint Surg 1951;33B:376-391.
8 Mann RA, Coughlin MJ: Adult hallux valgus; in Surgery of the Foot and Ankle, ed 6. St Louis, Mosby, 1993, pp 167-296.

$>9$ Coughlin MJ: Instructional Course Lectures, American Academy of Orthopaedic Surgeons - Hallux Valgus. J Bone Joint Surg Am 1996;78:932-966.

10 Ross FD: The relationship of abnormal foot pronation to hallux abducto valgus: a pilot study. Prosthet Orthot Int 1986;10:72-78.

$>11$ Resch S, Ryd L, Stenstrom A, et al: Measuring hallux valgus: a comparison of conventional radiography and clinical parameters with regard to measurement accuracy. Foot Ankle Int 1995; 16:267-270.

12 Garrow AP, Papageorgiou A, Silman AJ, et al: The grading of hallux valgus. The Manchester scale. J Am Podiatr Med Assoc 2001;91:7478.

13 D’Arcangelo PR, Landorf KB, Munteanu SE, et al: Radiographic correlates of hallux valgus severity in older people. J Foot Ankle Res 2010;3:20.

14 Menz HB, Munteanu SE: Radiographic validation of the Manchester scale for the classification of hallux valgus deformity. Rheumatology 2005;44:1061-1066.

15 Menz HB, Fotoohabadi MR, Wee E, et al: Validity of self-assessment of hallux valgus using the Manchester scale. BMC Musculoskelet Disord 2010;20:215-221.
16 Pique-Vidal C, Vila J: A geometric analysis of hallux valgus: correlation with assessment of severity. J Foot Ankle Res 2009;14:2-15.

17 Iliou K, Paraskevas G, Kanavaros P, et al: Relationship between pedographic analysis and the Manchester scale in hallux valgus. Acta Orthop Traumatol Turc 2015;49:75-79.

18 Schneider W, Knahr K: Surgery for hallux valgus. The expectations of patients and surgeons. Int Orthop 2001;25:382-385.

19 Roddy E, Zhang W, Doherty M: Prevalence and association of hallux valgus in a primary care population. Arthritis Rheum 2008;59: 857-862.

20 Pique-Vidal C, Sole MT, Antich J: Hallux valgus inheritance: pedigree research in 350 patients with bunion deformity. J Foot Ankle Surg 2007;46:149-154.

21 Spink MJ, Menz HB, Lord SR: Distribution and correlates of plantar hyperkeratotic lesions in older people. J Foot Ankle Res 2009; 2:1-7.

22 Menz HB, Roddy E, Thomas E, et al: Impact of hallux valgus severity on general and footspecific health-related quality of life. Arthritis Care Res (Hoboken) 2011;63:396-404. 